\title{
Membrane damage of bacteria by silanols treatment
}

\author{
Yun-mi Kim \\ Department of Materials Science and Engineering \\ University of Florida \\ Gainesville, FL 32611, USA \\ Tel: 1352 846-3793 \\ Fax: 1352 846-3355 \\ E-mail: yunmi740@ufl.edu \\ Samuel Farrah \\ Department of Microbiology and Cell Science \\ University of Florida \\ Gainesville, FL 32611, USA \\ Tel: $1352392-5925$ \\ Fax: 1352 392-5922 \\ E-mail: sfarrah@ufl.edu \\ Ronald H. Baney* \\ Department of Materials Science and Engineering \\ University of Florida \\ Gainesville, FL 32611, USA \\ Tel: 1352 846-3785 \\ Fax: 1352 846-3355 \\ E-mail: rbane@mse.ufl.edu \\ Website: http://baney.mse.ufl.edu
}

Financial support: Air Force Research Lab. in Tyndall Air Force Base.

Keywords: antimicrobials, hydrophobicity, organosilicon compounds.

\begin{abstract}
Antimicrobial action of silanols, a new class of antimicrobials, was investigated by transmission electron microscopy and fluorescent dye studies. Gramnegative bacteria, Escherichia coli and Pseudomonas aeruginosa and Gram-positive bacteria, Staphylococcus aureus and Enterococcus faecalis were treated by silanols at concentration of less than $0.2 \mathrm{wt} \%$ for one hour. Membrane damage of the bacteria by the silanol treatment was clearly observed by transmission electron microscopy. Separation of the cytoplasmic membrane from the outer membrane for $E$. coli and disorganized cytoplasmic membrane of the Gram-positive bacteria were observed when compared to the control. Fluorescent dyes, green-fluorescent nucleic acid stain (Syto 9) and the red-fluorescent nucleic acid stain (Propidium iodide), were used to monitor membrane damage of the bacteria by Confocal microscopy and Spectrophotometer. A reduction of the green fluorescent emission was detected for silanol treated bacteria indicating membrane damage of the bacteria and supporting the hypothesis that their viability loss may be due to their membrane damage analogus to alcohols.
\end{abstract}

Silanols, alcohols, and aromatic alcohols (phenols) have

*Corresponding author similar chemical structures consisting of a hydrophilic hydroxyl group and hydrophobic organic substitutents. Alcohols and phenols are widely used antimicrobial agents while the silanols were recently discovered to be strong biocidal agents in comparison with structurally analogous carbinols (Kim et al. 2006). Silicon is more electropositive than the carbon. The silicon atom is larger than the carbon atom and it can accommodate extra coordination providing. For example, the enzymatic action of the recently reported silicatine is believed to proceed through extra coordination at silicon (Shimizu et al. 1998). Both effects could provide possible different interaction pathways with cells. It is not unreasonable to suggest, however, that the antimicrobial mode of actions of the silanols might resemble those of the alcohols and the phenols. It is generally known that alcohols cause membrane damage (Mcdonnell and Russell, 1999; Etschmann et al. 2002) through an increase of the lipid solubility. In other words, alcohols increase the membrane fluidity through disorder of the biological selfassembly of the membrane. The primary target site of the phenolic compounds is the cytoplasmic membrane of bacteria (Mcdonnell and Russell, 1999). The damage to the cytoplasmic membrane causes the membrane to lose its ability to be a permeability barrier, subsequently leading to a loss of structural integrity and a leakage of intracellular material. 


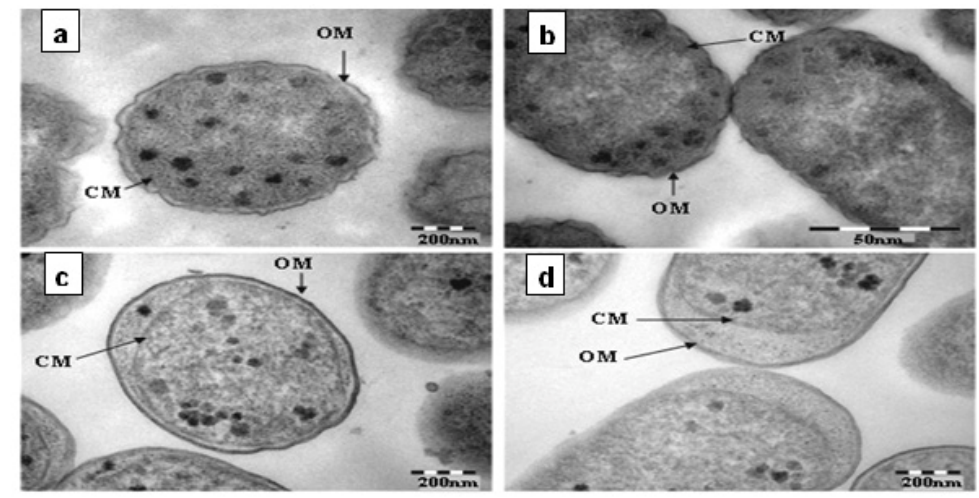

Figure 1. E. coli TEM pictures (a) and (b) are the control samples; (c) and (d) are triethylsilanol treated samples.

Silanols are environmentally friendly materials because they are rather quickly degraded into environmentally benign silica, carbon dioxide and water in the environment (Graiver et al. 2003). Silanols can be applied by a various delivery systems such as a neat liquid phase, vapor phase due to their high volatility. In addition, unlike their analgous carbinols, silanols can be employed as controlled release agents through release by hydrolysis of Si-O-C bonds from carbinol baring substrates. This is quite analogus to the "blocking agents" employed in the pharmaceutical industry. These novel biocide silanols can be prepared from low cost intermediates derived from the commercial processes associated with the silicone industry.

A bacterium has several layers of material that enclose or protect its cytoplasm (Moat et al. 2002; Barton, 2005). The cytoplasm region contains critical life units protected by the plasma membrane and the cell wall. In the Gram-positive bacteria, such as $S$. aureus and E. faecalis, the cell wall is thick (15-80 nanometers) consisting of several layers of peptidoglycan. On the other hand, Gram-negative bacteria such as $E$. coli and $P$. aeruginosa have a relatively thin (10 nanometers) cell wall surrounded by an outer membrane. The membranes are a bilayered structure and a selective permeability barrier that regulates the passage of substances into and out of the cell. The plasma membrane is the last barrier that can separate or protect the cytoplasm from the environment (Moat et al. 2002; Barton, 2005). Both electrostatic and hydrophobic interactions are involved in maintaining the spatial organization of the membrane components (Ingram and Buttke, 1984). It is well accepted that disorganization of the membrane by undesired or foreign substances can cause loss of the permeability or of the integrity of the membrane. This ultimately cause the death of the cell.

For many antimicrobial agents, antimicrobial actions are initiated by interactions of the biocides with the cell wall membrane of the microorganisms. The agents then penetrate into the cell and finally act at the target sites (Mcdonnell and Russell, 1999). Hunt (1975) proposed that the potency of aliphatic alcohols is directly related to their lipid solubility. The lipid in the membrane bilayers can be dissolved by alcohols through the induced hydrophobic interaction between the alkyl chain from the alcohols and the lipid region in the membrane (Hunt, 1975; Ingram and Buttke, 1984). The hydrophobicity is an important parameter with respect to toxicity or alternation of the membrane's integrity because it is directly related to the membrane permeation, which can result in disruption of the membranes of the bacterium. A plasma membrane integrity test with short-chain aliphatic alcohols illustrated that an increase of the alkyl chain length from methanol to 1octanol enhanced the loss of the membrane integrity of epithelial cells in vitro (McKarns et al. 1997). Those authors suggested that alteration of the membrane integrity correlates with the hydrophobic properties of the alcohols.

In this study we suggest that the hydrophobic interaction occurs between the organic group of the silanols and the lipophilic portion of the membranes as well as the hydrogen bonding between the hydroxyl function of the silanol and either the ester linkages of fatty-acyl residues or water molecules (Ingram and Buttke, 1984). We hypothesize that the silanol can partition effectively into the membrane through these interactions and cause its disorganization by increasing lipid solubility. Transmission electron microscopy and fluorescent dye techniques were utilized to verify our hypothesis of the membrane damage on the bacteria treated by silanols.

\section{MATERIALS AND METHODS}

\section{Bacterial preparations and antimicrobial test procedure}

The bacterial strains employed were the Gram-negative bacteria, E. coli C3000 (ATCC 15597) and a laboratory strain of $S$. aureus provided by the Department of Microbiology at the University of Florida and the Grampositive bacteria, $P$. aeruginosa type strain (ATCC 10145) and E. faecalis type strain (ATCC 19433). The bacteria suspensions were prepared according to the procedure by Rincón and Pulgarin (2003). The bacteria were inoculated 


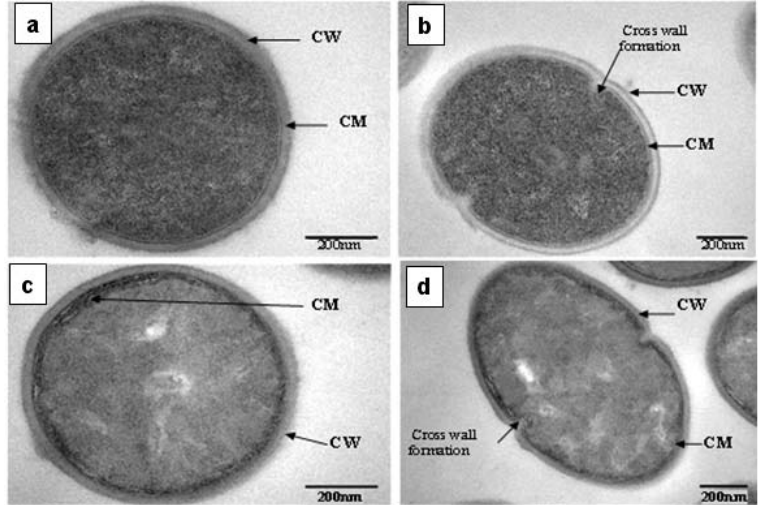

Figure 2. E. faecalis TEM pictures (a) and (b) are the control samples; (c) and (d) are triethylsilanol treated samples.

into a flask containing $90 \mathrm{ml}$ of autoclaved water and $10 \mathrm{ml}$ of Columbia broth and incubated for $20-24 \mathrm{hrs}$ at $37^{\circ} \mathrm{C}$ with constant agitation, $200 \mathrm{rpm}$, under aerobic conditions. The bacterial cells were collected by centrifugation at $500 \mathrm{rcf}$ (relative centrifugal force) for $10 \mathrm{~min}$ at $4^{\circ} \mathrm{C}$ and washed 3 times with sterilized deionized water. A bacterial pellet was resuspended in the sterilized water after final washing. The concentrations of the prepared bacteria suspensions prepared were $2-6 \times 10^{8} \mathrm{cfu} / \mathrm{ml}$ (colony forming units $/ \mathrm{ml}$ ).

The antimicrobial activity tests were carried out in aqueous condition (Cremieux and Davin-Regli, 2000) by adding a given concentration of antimicrobial agent to $9 \mathrm{ml}$ of medium, deionized water, and $1 \mathrm{ml}$ of the bacterial suspension. Triethylsilanol received from Gelest, Inc. and synthesized phenethyldimethylsilanol were used as the antimicrobials. The purity of the silanols measured by $\mathrm{H}-1$ NMR (Nuclear Magnetic Resonance) showed $95 \pm 3 \%$ for triethylsilanol and $90 \pm 3 \%$ for phenethyldimethylsilanol. The impurity of the silanols was disiloxane, a condensation by-product of the silanols. The antimicrobial activity of the disiloxane was insignificant (Kim et al. 2006). The solution was mixed for an hour with constant stirring at room temperature. One millilitre sample was collected after a 1 hour treatment for the viability test. Viabilities of treated bacteria were confirmed by the plate-count method (Harrigan, 1998; Spencer and Ragout de Spencer, 2001).

\section{TEM sample preparation procedures}

Bacterial suspensions, E. coli, $P$. aeruginosa, $S$. aureus, and E. faecalis, were treated by triethylsilanol at a concentration of $0.2(\% \mathrm{~g} / \mathrm{g})$ for $1 \mathrm{hr}$. The control was prepared from the same batch of bacterial suspension at the same condition as the treated one. The plate count method confirmed no bacteria growth after the triethylsilanol treatment. The control and the treated bacteria suspension were centrifuged at $2600 \mathrm{rpm}$ for $5 \mathrm{~min}$ and washed with a buffer solution $0.1 \mathrm{M}$ sodium cacodylate, $\mathrm{pH}$ 7.2-7.4. Primary fixation of the bacteria consisted of a 1:1 mixture of a $1 \%$ solution of $\mathrm{OsO}_{4}$ containing $7.5 \mathrm{mg}$ of potassium ferricyanide per $\mathrm{ml}$ and a buffer solution containing 5\% glutaraldehyde (Hasty and Hay, 1978). Five millilitre of the primary fixation solution was added to the bacteria. They were fixed for 1 $\mathrm{hr}$, followed by centrifugation and washing with the buffer 2 times and 3 times with deionized water for $10 \mathrm{~min}$. An ethanol graded dehydration series $(25 \%-100 \%)$ was used to dehydrate the sample for $20 \mathrm{~min}$, followed by $100 \%$ acetone for $15 \mathrm{~min}$. The samples were infiltrated and embedded in Embed 812 epoxy resin (Yenugu et al. 2004). Ultra thin sections $(70 \mathrm{~nm})$ were obtained by microtome and placed on 400 mesh uncoated copper grids. Post staining was done with $2 \%$ uranyl acetate and Reynold's lead citrate. The samples were examined and photographed at an accelerating voltage of $75 \mathrm{kV}$ using a Hitachi H-7000 transmission electron microscopy at the Electron Microscopy Core Laboratory at the University of Florida.

\section{Fluorescent dye method}

Fluorescent dye, "LIVE/DEAD" BacLight Bacterial Viability Kits provided by Molecular Probes, have the capability of monitoring the viability of the bacteria as a
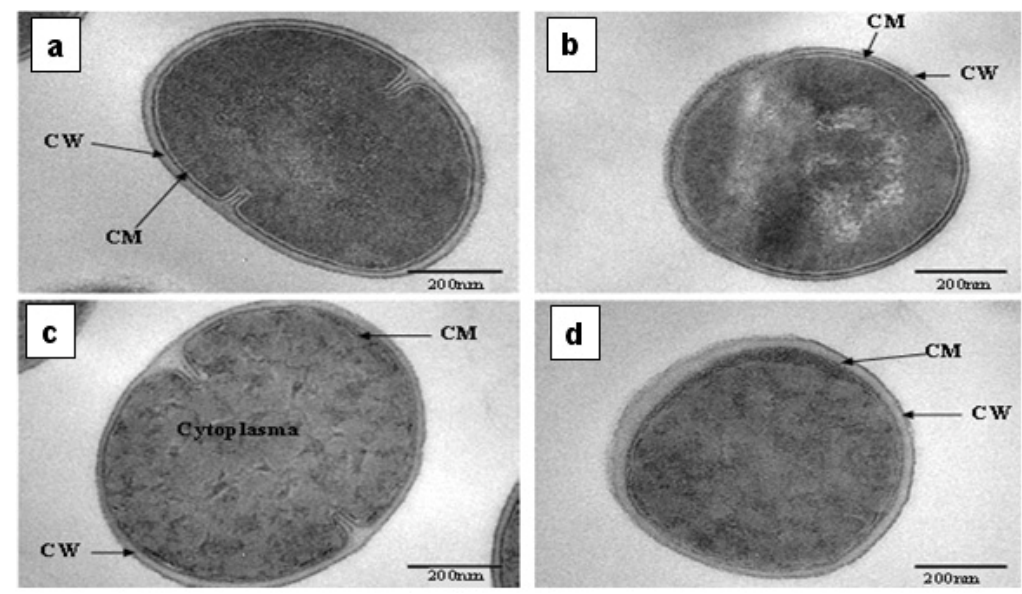

Figure 3. S. aureus TEM pictures (a) and (b) are the control samples; (c) and (d) are triethylsilanol treated samples. 

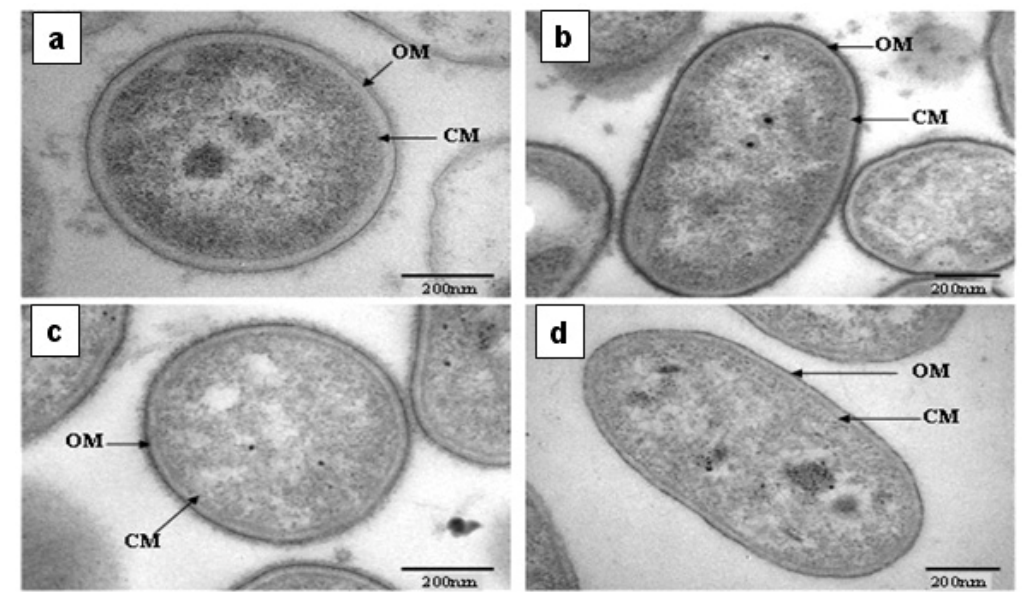

Figure 4. $P$. aeruginosa TEM pictures (a) and (b) are control samples; (c) and (d) are triethylsilanol treated samples.

function of the cell's membrane integrity (Bunthof et al. 2001; Laflamme et al. 2004). Bacteria with a compromised membrane that are considered to be dead or dying will stain red, whereas cells with an intact membrane will stain green. The Viability Kit (L7007) is composed of green-fluorescent nucleic acid stain (Syto 9) and the red-fluorescent nucleic acid stain (Propidium iodide). The red and the green stain show a difference in spectral characteristics, different emission wavelength, and in their ability to penetrate healthy bacterial cells. The green stain can label bacteria with intact membranes and with damage membranes. In contrast, the red stain penetrates only bacteria with damaged membranes and causes a reduction in the green fluorescence when both dyes are present. The excitation /emission range of the green stain is $470 / 510-540 \mathrm{~nm}$ and $470 / 620-650 \mathrm{~nm}$ for the red stain.

The fluorescent dye kit has the green stain, $3.34 \mathrm{mM}$ in DMSO, and the red stain, $20 \mathrm{mM}$ in DMSO. Equal volumes of the red and the green dye are combined in a microfuge tube and mixed thoroughly for $1 \mathrm{~min}$. Three microlitre of the dye mixture was added to each of the $1 \mathrm{ml}$ of bacterial suspensions, mixed thoroughly, and kept in the dark for about $15 \mathrm{~min}$. Fluorescence microscopy and fluorescence spectrophotometer methods were used to evaluate the viability of the bacteria as a function of the membrane integrity.

\section{Fluorescence microscopy}

Five microlitre of the stained bacterial suspension was placed between a slide and a cover slip for microscopy evaluation. MRC-1024 confocal laser scanning microscopy at the McKnight Brain Institute at the University of Florida was used for observation of the stained bacteria at a magnification of 40X. The "LaserSharp" software employed in this study can deliver simultaneous three channels acquisition and display. The channels for red dye and green dye acquired the picture and were displayed simultaneously, then the combined picture of these two dyes was also displayed.

\section{Fluorescence spectrophotometer}

One millilitre of the stained bacterial suspension was placed in a quartz rectangular spectrophotometer cell. The cell has Suprasil quartz windows with a $10 \mathrm{~mm}$ light path. The fluorescence emission was measured at the emission spectrum (excitation $470 \mathrm{~nm}$, emission $500-700 \mathrm{~nm}$ ) by a Perkin-Elmer MPF-44B fluorescence spectrophotometer at the Particle Engineering Research Center at the University of Florida.

\section{RESULTS AND DISCUSSION}

\section{Membrane damage of bacteria by silanols treatment - TEM}

Transmission electron microscopy revealed structural membrane damage for the four bacteria, E. coli, $P$. aeruginosa, $S$. aureus, and E. faecalis, treated by triethylsilanol for $1 \mathrm{hr}$ at the minimum lethal concentration of $0.2(\% \mathrm{~g} / \mathrm{g})$. The minimum lethal concentration (MLC) was defined as the concentration required for a 7-log reduction in viable bacteria after $1 \mathrm{hr}$ exposure period in this study. The plate count method supported a complete deactivation of the bacteria after the silanol treatment, meaning $99.99999 \%$ elimination of the viable bacteria. A smooth continuous membrane structure was clearly observed in the untreated bacteria while the treated bacteria showed relatively disorganized membrane structures. Primary fixation allows the membrane structures to be preserved. Glutaraldehyde cross linked the proteins and $\mathrm{OsO}_{4}$ cross linked the lipids. Since the triethylsilanol treated bacteria and the control cell were processed by the same procedure the differences observed were caused by the silanol treatment.

The membranes were clearly identified in the TEM pictures 

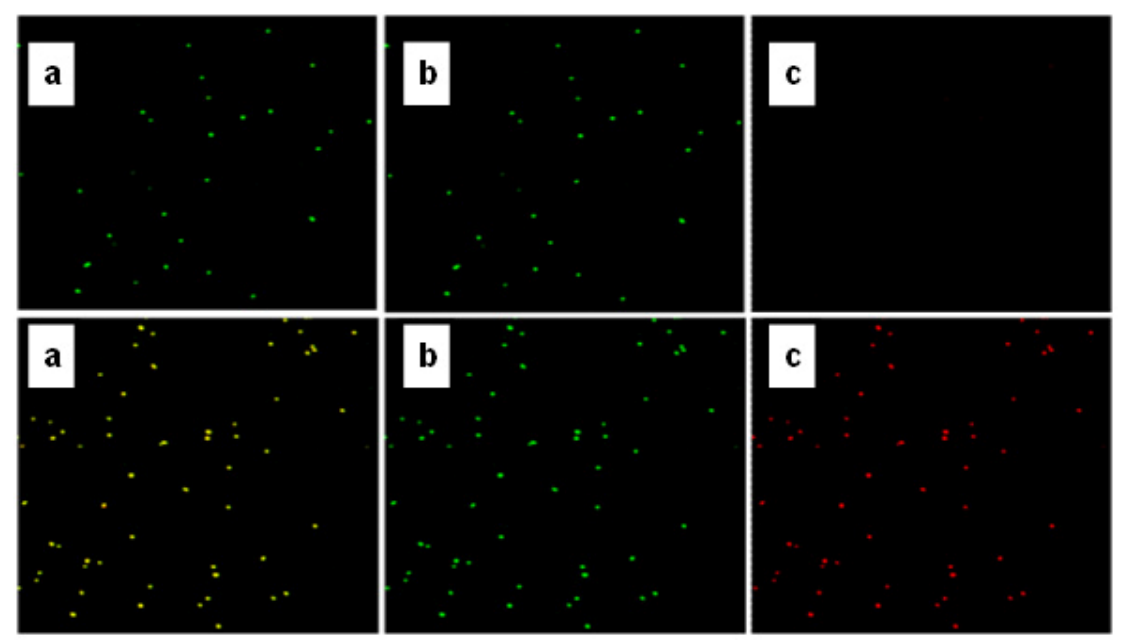

Figure 5. Fluoresecent microscopy pictures of E. coli, control (top figures) and triethylsilanol treated (bottom figures). (a) is combined picture of (b) and (c), (b) is only for green light, and (c) is only for red light.

due to the primary fixation of $\mathrm{OsO}_{4}$ and the post staining of the bacteria. The dark areas show where the sample had a high electron density and the light areas show where the sample had a low electron density (Anderson et al. 2004). A general observation of $E$. coli treated by triethylsilanol was that the cytoplasmic membrane (CM) appeared to be retracted from the outer membrane (OM) and disorganized whereas the control showed an intact cell envelope between the outer membrane and the cytoplasmic membrane as shown in Figure 1. Corre et al. (1990) reported that membrane alteration of E. coli, P. aeruginosa, and $S$. aureus occurred with a phenethyl alcohol treatment. These authors claimed that the Gram-negative cell envelops were permeabilized and the plasmic membrane in $S$. aureus was solubilized with phenethyl alcohol treatment. The cell wall (CW) dissociation from the cytoplasmic membrane of $E$. coli was reported as well as enlargement of the cell wall of $S$. aureus upon phenethyl alcohol treatment (Corre et al. 1990). In the Gram-positive bacteria, E. faecalis and $S$. aureus, the cytoplasmic membrane disruptions are clearly visible as seen in Figure 2 and Figure 3 respectively. The cytoplasmic membrane lost its integrity and showed disordered structures when compared to the control, which shows a smooth and intact membrane. Unlike the result from the phenethyl alcohol treatment on $S$. aureus (Corre et al. 1990) the enlargement of the cell wall of the Grampositive bacteria are not noticeable for the triethylsilanol treated bacteria. Cross wall formation was observed in the Gram-positive bacteria, indicative of cell division. The silanol treated $S$. aureus also showed a cytoplasmic region that appears to be inhomogeneous when compared to the control as shown in Figure 3. The inhomogeneous
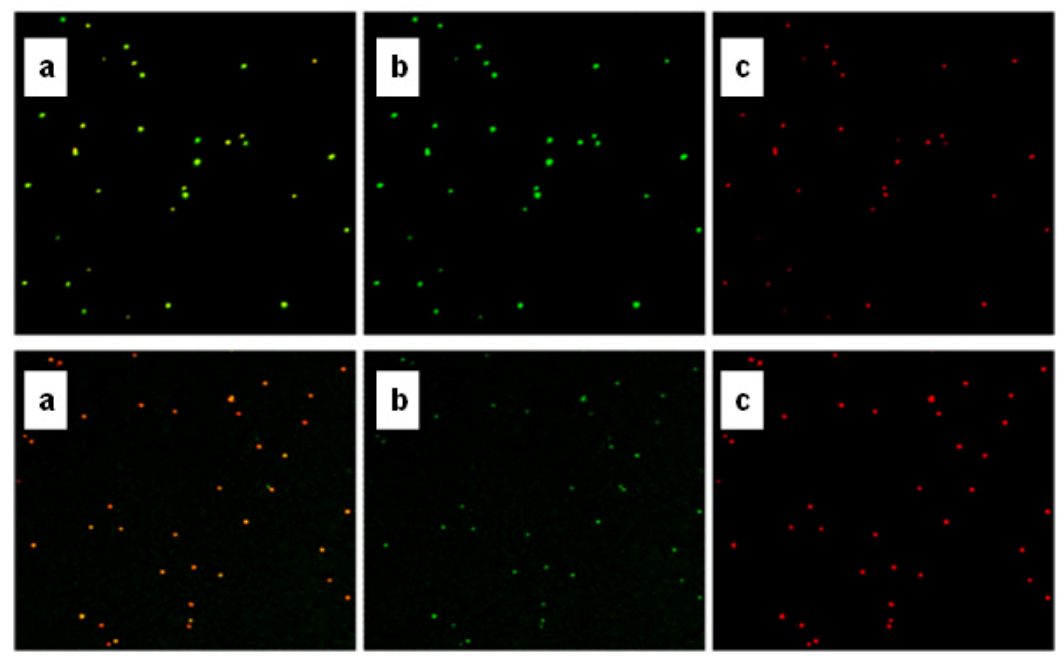

Figure 6. Fluoresecent microscopy pictures of E. faecalis, control (top figures) and triethylsilanol treated (bottom figures). (a) is combined picture of (b) and (c), (b) is only for green light, and (c) is only for red light. 
appearance of the cytoplasm might be the result of segregation of the internal organelles. A rough surface on the outer membrane structure was detected on treated $P$. aeruginosa when compared to the smooth and continuous outer membrane of the untreated bacterium shown in Figure 4. However, a difference between the treated and the control for $P$. aeruginosa was relatively insignificant. It is reasonable to speculate that a loss of integrity of the membranes by the silanol treatment may lead to malfunction of the permeability barrier and could be one of reasons that cause loss of their viability.

\section{Membrane damage of the bacteria by silanols treatment - Fluorescent dye studies}

Membrane damage due to the silanols treatment was monitored by using fluorescent dye through fluorescence microscopy and fluorescence spectrophotometry. Four bacterial suspensions without the silanol treatment were tested as control and compared with bacteria treated by the silanols. As expected, the silanol treated bacteria exhibited a reduced green fluorescence light and an increased red fluorescence light. Penetration of the red dye into the bacteria with damaged membrane led to a reduction of the
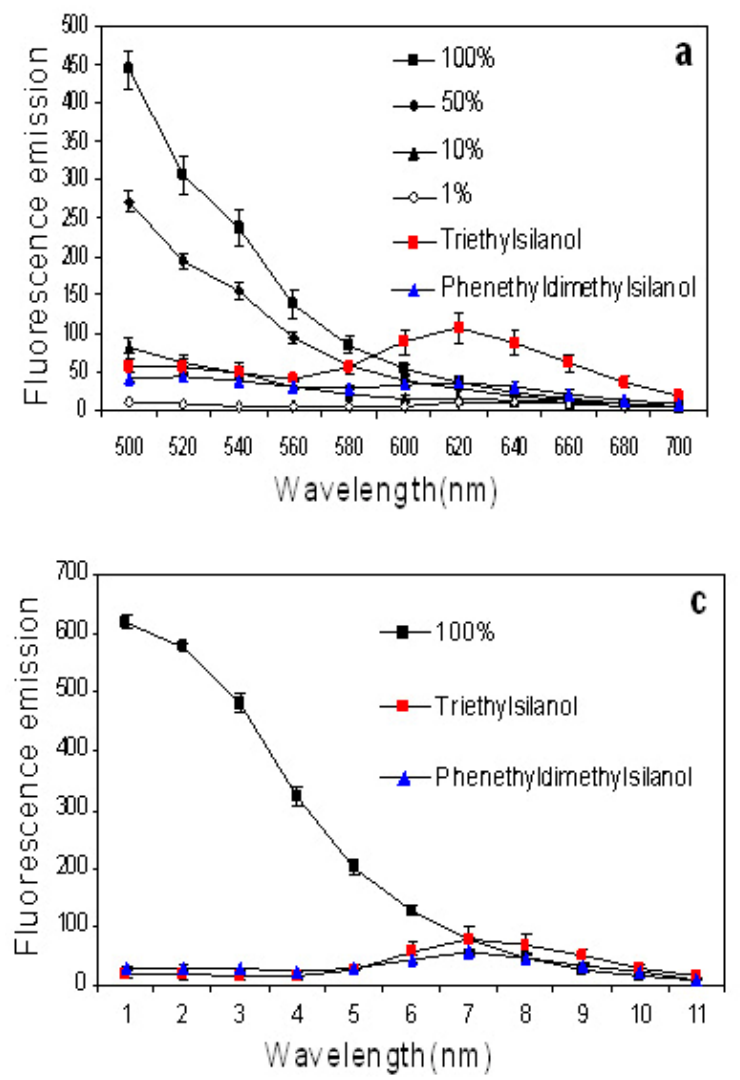

green light. As a result, the silanol treated bacteria showed a double staining fluorescence light with a strong red and a weak green light under fluorescence microscopy as displayed in the bottom figures of Figure 5 for $E$. coli and Figure 6 for E. faecalis. In comparison, bacteria without the silanol treatment showed mostly green light in the case of the Gram-negative bacteria as seen in the top figures of Figure 5, while a strong green light and a weak red light was detected for the Gram-positive bacteria as seen in the top figures of Figure 6. P. aeruginosa and $S$. aureus displayed the similar results. Three fluorescence microscopy pictures for each bacterium are displayed to verify the reduction of the green light in bacteria. In Figure $5, E$. coli, figure A is a combined picture of B and C, B is only for green light and $\mathrm{C}$ is only for red light. It should be mentioned that bacteria showed in figure $\mathrm{B}$ and figure $\mathrm{C}$ from Figure 5 are exactly the same E. coli, indicating the double staining on the bacteria. E. faecalis in Figure 6 showed the similar results. Laflamme et al. (2004) characterized bacterial viability as a function of membrane integrity using fluorescent dye, SYTO 9 and Propidium iodide. In spores with compromised membrane, double staining was detected, and showed that the red light was
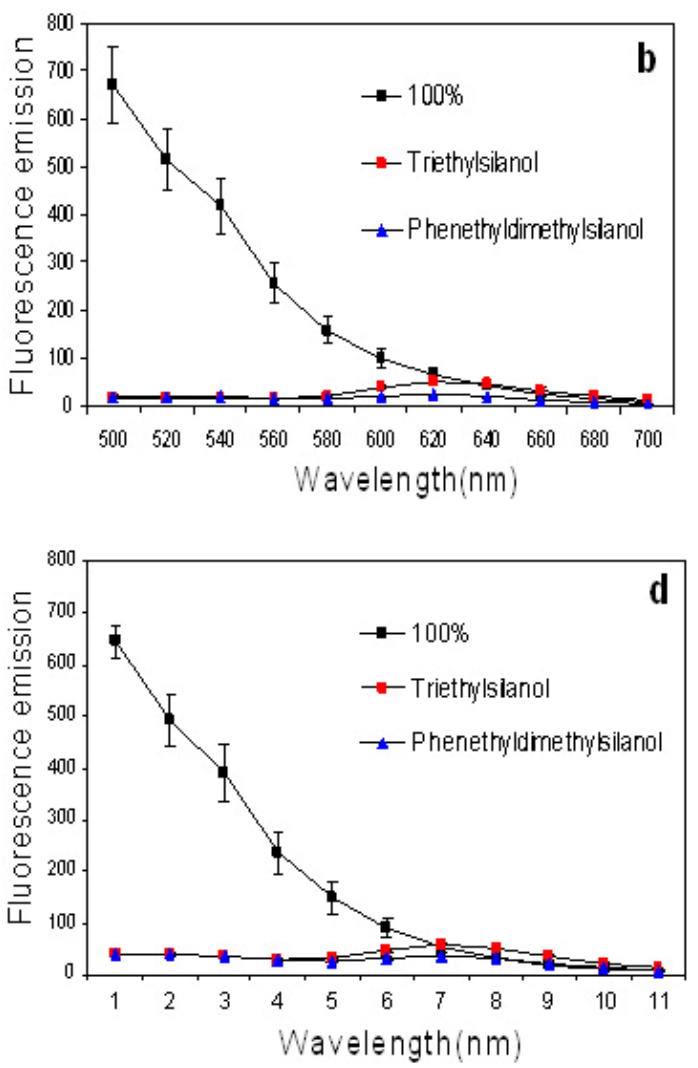

Figure 7. Fluorescence spectrophotometer data for the stained bacteria at emission wavelength $500-700 \mathrm{~nm}$ with $470 \mathrm{~nm}$ excitation wavelength.

(a) E. coli.

(b) $P$. aeruginosa.

(c) E. faecalis.

(d) S. aureus. 
brighter than the green light.

Fluorescence spectrophotometry provides quantitative results (Wu et al. 1999) suggesting a reasonable explanation regarding the fluorescence microscopy results. Different concentrations of bacterial suspensions were prepared by diluting from $100 \%$ to $50 \%, 10 \%$, and $1 \%$ as controls. The fluorescence emissions of each concentration were measured by the spectrophotometer at a wavelength of excitation of $470 \mathrm{~nm}$ and an emission of 500-700 nm. A relative intensity of the fluorescence emissions at the range between 500 and $550 \mathrm{~nm}$ in wavelength where the green light is detected was differentiated depending on the concentration of the bacteria as seen in Figure $7 \mathrm{a}$. Fluorescence emission corresponding to $10 \%$ bacterial concentration represents a $1 \log$-reduction and $1 \%$ is for a 2 log-reduction of viable bacteria. Fluorescence emissions of bacterial suspensions treated by the silanols were compared with the controls. A significant reduction of fluorescence emission at the green light emission wavelength of 500-550 $\mathrm{nm}$ was observed for the treated bacteria when compared to the $100 \%$ control sample as shown in Figure 7 . The red dye penetrated into the bacteria with compromised membrane and reduced the green light. An increase of red light emission at 620-650 nm wavelength was also displayed for the treated bacteria. The extent of increase of red light was relatively small except for $E$. coli with triethylsilanol treated shown in Figure 7a.

The fluorescence spectrophotometer results showed only a 1 or 2-log reduction of viable bacteria for the silanol treated samples even though the plate count method confirmed a 7log-reduction of the treated bacteria. This result is consistent with the fluorescence microscopy result showing double staining for treated bacterial suspension. In other words, the fluorescence emission did not show a zero emission of green light or indicate a 7-log-reduction because the green dye is present with the red dye as double staining for the treated bacteria. The reduction of the green fluorescence light as well as the increase of the red fluorescence light was observed as an indication of the membrane damage of the silanol treated bacteria.

In summary, the mechanism of action of the silanols upon the cell membrane of the bacteria was investigated. A change in the membrane after the silanols treatment was detected by transmission electron microscope, showing a detachment of the plasma membrane from the outer membrane for E. coli. In the case of the Gram-positive bacteria a disorganized cytoplasmic membrane was observed upon the silanol treatment when compared to the smooth and intact cell membrane of the untreated bacteria. The fluorescence method allowed us to monitor bacteria viability based on the membrane damage because the red dye only penetrates into the bacteria with membrane damage, subsequently reducing the green fluorescence. A significant reduction of the green light, was demonstrated by fluorescent microscopy and spectrophotometer, suggesting that the bacteria treated by the silanols had compromised membranes. The membrane damage might be one of causes for the death of the viable bacteria.

\section{ACKNOWLEDGMENTS}

We are grateful to Dr. Ben Koopman for allowing us to use his Microbiology laboratory. The authors would like to thank to ICBR Electron Microscope Core Laboratory for TEM and McKinght Brain Institute for Confocal Microscope.

\section{REFERENCES}

ANDERSON, Rachel Claire; HAVERKAMP, Richard G. and YU, Pak-Lam. Investigation of morphological changes to Staphylococcus aureus induced by ovine-derived antimicrobial peptides using TEM and AFM. FEMS Microbiology Letters, November 2004, vol. 240, no. 1, p. 105-110.

BARTON, Larry L. Structural and Functional Relationships in Prokaryotes. New York, Springer, 2005. 820 p. ISBN 0-38-720708-2.

BUNTHOF, Christine J.; VAN SCHALKWIJK, Saskia; MEIJER, Wilco; ABEE, Tjakko and HUGENHOLTZ, Jeroen. Fluorescent method for monitoring cheese starter permeabilization and lysis. Applied and Environmental Microbiology, September 2001, vol. 67, no. 9, p. 42644271.

CORRE, J.; LUCCHINI, J.J.; MERCIER, G.M. and CREMIEUX, A. Antibacterial activity of phenethyl alcohol and resulting membrane alterations. Research in Microbiology, May 1990, vol. 141, no. 4, p. 483-497.

CREMIEUX, A.F.J. and DAVIN-REGLI, A. Methods of Testing Disinfectants. In: BLOCK, S.S. ed. Disinfection, Sterilization, and Preservation. $5^{\text {th }}$ ed. Lippincott Williams and Wilkins, Philadelphia, 2000, p. 1305-1325.

ETSCHMANN, M.M.W.; BLUEMKE, W.; SELL, D. and SCHRADER, J. Biotechnological production of 2phenylethanol. Applied Microbiology and Biotechnology, June 2002, vol. 59, no. 1, p. 1-8.

GRAIVER, D.; FARMINER, K.W. and NARAYAN, R. A review of the fate and effects of silicones in the environment. Journal of Polymers and the Environment, October 2003, vol. 11, no. 4, p. 129-136.

HARRIGAN, Wilkie F. Laboratory Methods in Food Microbiology. $3^{\text {rd }}$ ed. San Diego, Academic Press, 1998. 532 p. ISBN 0-12-326043-4.

HASTY, D.L. and HAY, E.D. Freeze-fracture studies of the developing cell surface. II. Particle-free membrane blisters on glutaraldehyde-fixed corneal fibroblasts are artefacts. The Journal of Cell Biology, September 1978, vol. 78, no. 3, p. $756-768$. 
HUNT, W.A. The effects of aliphatic alcohols on the biophysical and biochemical correlates of membrane function. Advances in Experimental Medicine and Biology, 1975, vol. 56, p. 195-210.

INGRAM, L.O. and BUTTKE, T.M. Effects of Alcohols on Micro-Organisms. In: ROSE, Anthony H. and TEMPEST, David W. eds. Advances in Microbial physiology. New York, London, Academic press, 1984, vol. 25, p. 280-282.

KIM, Yun-Mi; FARRAH, Samuel and BANEY, Ronald H. Silanol - A novel class of antimicrobial agent. Electronic Journal of Biotechnology [online]. 15 April 2006, vol. 9, no. 2. Available from Internet: http://www.ejbiotechnology.info/content/vol9/issue2/full/4/ index.html. ISSN 0717-3458.

LAFLAMME, C.; LAVIGNE, S.; HO, J. and DUCHAINE, C. Assessment of bacterial endospore viability with fluorescent dyes. Journal of Applied Microbiology, April 2004, vol. 96, no. 4, p. 684-692.

MCDONNELL, Gerald and RUSSELL, A. Denver. Antiseptics and disinfectants: Activity, action, and resistance. Clinical Microbiology Reviews, January 1999, vol. 12 , no.1, p. 147-179.

MCKARNS, Susan C.; HANSCH, Corwin; CALDWELL, William S.; MORGAN, Walter T.; MOORE, Sarah K. and DOOLITTLE, David J. Correlation between hydrophobicity of short-chain aliphatic alcohols and their ability to alter plasma membrane integrity. Fundamental and Applied Toxicology, March 1997, vol. 36, no. 1, p. 6270 .

MOAT, Albert G.; FOSTER, John W. and SPECTOR, Michael P. Microbial Physiology. $4^{\text {th }}$ ed. New York, WileyLiss, 2002. 736 p. ISBN 0-471-39483-1.

RINCÓN, A.G. and PULGARIN, C. Photocatalytical inactivation of $E$. coli: effect of (continuous-intermittent) light intensity and of (suspended-fixed) $\mathrm{TiO}_{2}$ concentration. Applied Catalysis B: Environmental, August 2003, vol. 44, no. 3, p. 263-284.

SHIMIZU, Katsuhiko; CHA, Jennifer; STUCKY, Galen D. and MORSE, Daniel E. Silicatein alpha: Cathepsin L-like protein in sponge biosilica. Proceedings of the National Academy of Sciences of the United States of America, May 1998, vol. 95, no. 11, p. 6234-6238.

SPENCER, John F.T. and RAGOUT DE SPENCER, Alicia L. Food Microbiology protocols. New Jersey, Humana Press, 2001. 495 p. ISBN 0-89603-867-X.

WU, Manhong; MAIER, Elke; BENZ, Roland and HANCOCK, Robert E.W. Mechanism of interaction of different classes of cationic antimicrobial peptides with planar bilayers and with the cytoplasmic membrane of
Escherichia coli. Biochemistry, 1999, vol. 38, no. 22, p. 7235-7242.

YENUGU, Suresh; HAMIL, Katherine G.; FRENCH, Frank S. and HALL, Susan H. Antimicrobial actions of the human epididymis 2 (HE2) protein isoforms, HE2alpha, HE2beta1 and HE2beta2. Reproductive Biology and Endocrinology, August 2004, vol. 2, no. 61, p. 1-17. 